\title{
Dialectiek van het onderzoek in de huisartsgeneeskunde
}

Citation for published version (APA):

Knottnerus, J. A. (1988). Dialectiek van het onderzoek in de huisartsgeneeskunde. Rijksuniversiteit Limburg. https://doi.org/10.26481/spe.19880929ak

Document status and date:

Published: 29/09/1988

DOI:

10.26481/spe.19880929ak

Document Version:

Publisher's PDF, also known as Version of record

\section{Please check the document version of this publication:}

- A submitted manuscript is the version of the article upon submission and before peer-review. There can be important differences between the submitted version and the official published version of record.

People interested in the research are advised to contact the author for the final version of the publication, or visit the DOI to the publisher's website.

- The final author version and the galley proof are versions of the publication after peer review.

- The final published version features the final layout of the paper including the volume, issue and page numbers.

Link to publication

\footnotetext{
General rights rights.

- You may freely distribute the URL identifying the publication in the public portal. please follow below link for the End User Agreement:

www.umlib.nl/taverne-license

Take down policy

If you believe that this document breaches copyright please contact us at:

repository@maastrichtuniversity.nl

providing details and we will investigate your claim.
}

Copyright and moral rights for the publications made accessible in the public portal are retained by the authors and/or other copyright owners and it is a condition of accessing publications that users recognise and abide by the legal requirements associated with these

- Users may download and print one copy of any publication from the public portal for the purpose of private study or research.

- You may not further distribute the material or use it for any profit-making activity or commercial gain

If the publication is distributed under the terms of Article $25 \mathrm{fa}$ of the Dutch Copyright Act, indicated by the "Taverne" license above, 
Dialectien van thet onderzoek

in de huisartsgeneeskunde

\section{Rede}

ultgesproken bij de

anvaarding van het ambt van

qewoon hooglerar in de huisartsgeneskunde

an de Rijksunirersiteit Limburg

op donderdag 29 september

door

Dr. J.A. Rnottnerus 


\section{Inleiding}

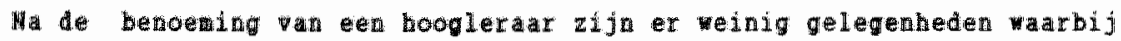
bet vanzelfspreked word gecht dat deze in het openbar een algenene visie geft op bet eigen vakgebied. Wet zelden blijt het bij het velbelovende enthousiase van de orerende beginer. Sons grijpt een hoogleral nog de kans ow op de valreep van het afscheid uit te leggen warow het buten eigen schuld allewal anders gelopen is dan verwacht. en hoe het in de toekongt dan wel zov noeten. Helas ontbreekt in de reqel bet belangrijkste: en tussentujuse evatie op basis van de inmidals opgebouwde erwaring en inzichten, eventueel witmondend in vertieutiag vall visies en bijstelling van voornemens. Ik stel darom, aan het begin wan dit eerste optreden, yoor on als gebruik in te vaeren dat boogleraren tijdeng de rit, ten inste on de vijf jaar, een poortgangrede uitspreken ten overstaan ran het openbare forum. 2elf ben ik in lk geval wan plan dat te doen.

Mar nu terug naar vandag.

In Wederland wordt 85 tot 90 procent van alle aan de gezondheidszorg angeboden problemen geheel binnen de huisartspraxtijk afgehandeld, en daarbij worden alle deelgebieden bestreken. HIke poging ow in deze rede bet vakgebied huisartsgeneeskunde te schetsen, is dan ook bij roorbat tot wiskken gedoemd. Mel zijn met dit cijfer het eminente belang en de reirwijdte wan het valirect angegeven, evenals twee centralle, elkaar anvullende elementen van bet huisartigeneeskundi handelen:

- het generalisme, op grond warvan het leeuwedeel van de problemen kan worden berkend en war nodio behandeld;

- de zeeffunctie, in het hader varvan verantworde beslissingen moeten worden genomen over het al dan niet vervijuten van paticatem en over de ward wan en eventuele verwijzing.

Gerien het in principe onbegrensde geneeskundige blikveld en de daraan verbonden professionele verantwoordelijkbeden, is het ontwiknelen, uitwoeren nar de praktjk terugvertalen wan wetenschappelijk onderzoek in de huitartsgeneeskunde verre van envoudig. On dezelfde redenen is deze ondermeming ook uiterrate boeiend en rellevant.

In deze constateringen liggen de nodige spaningsvelden besloten, die inberent zijn an de huisartsqeneeskundige vetenschap. Er dienen afweglingen plats te vinden, die men kan zien als onderdeel van een produktief dialectisch proces. De permanente opqave daarbij is het 
oplossen wan innerlijke tegenstellingen in ean ewheld vamogere orde. Ondat bet bil teen gelegenheid als deze passender is de toeboorder een bilk te gunnen 1 in onze wetenschappelijke keuken dan ben onze produkten an te prijzen, wil it u deelgenoot aken wan enkele van deze spanningsilden en afwegingen. Aan de orde zullen towen:

- de verbouding tussen het terugdringen van medicalisering het verrichten pan adische research in de huisartspraktijk:

- het spanningsveld tussen de integrale benadering van de buisarts en de qereducerde optiek van de onderzoker;

- de competitie tussen de relevantie en de onderzokbarbeid van onderzoksvragem;

- de relatie tussen het huisartsgeneeshundio ambacht en het onderzoek:

- diverse methodologische vragstukken.

Vervolgens zal ik andacht besteden an de inbedding van het huisartsgeneeskumi onderzoek in de regio, de kring van medische disciplines en het etenschappelijk beoordelingscircuit. Ik zal eindigen met en korte beoordeling van recente regeringswoornemens die het functioneren van de buisarts raken.

\section{Hedisch onderzoek versus medicalisering}

Wadat in de treede helft van de vorige eeuw de inmiddels wettelijk erkende bedische beroepsgroep was begonnen zich op te splitsen in specialisten en algemene artsen of huisartsen, kwamen rond de euwwisseling de discussies los ower het bestansrecht van de verschillende soorten medici de begrenzing van hus respectieve wakgebieden. De dqeween arts werd reeds toen voor we woeten geworpen dat hij zich op geen enkel deelqubied weer kon weten wet de dasbetreffonde opecializt. War boh verd al gewezen op de gevaren van eanzijdineid en vakidiotie: "Anectoten doen de ronde van tandartsen en seel-specialitien die zoozer in de zieken de zieke tanden en kelen beschouwen, dat hun eerst de naaw ea de bijzonderheden van den lijder te binnen schieten, wanneer eerst des lijders gebit of keel ter aarneming homt. War moet dit heen, zoo ragt nen aich en schijnbar niet zonder goede qronden af", aldus Huskens in zijn inaugurale rede in 1906. (1)

Wa de tweede wereldoorlog gingen huisartsen beseffen, dat ar woor hen en specifick werk- en ontwikklingsgebied bestond(2): het realiseren van een "continue, integrale en persoonlijke zoro voor de gezondheid 


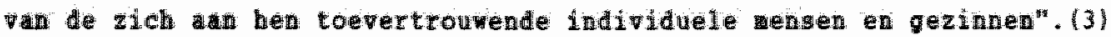
2* wolgde een inhalmanoeuwre varbij wooral axdacht werd besteed aam de gedrafswetenschappelifke haten van het vak en - darmee verbonden de interdociplinare samwerking in de exste lijn. Bij bet explorerem an dez achtergebleven gebiedein door budel wa onderzoeh vervulden gedragwetensehappers anzelfsprekend een richtirgoevende rol en werden door hen fundamentele bijdragen geleverd. hat hierdoor in de jareb zeventig verd bereikt, kan men zonder weer een hoogtepunt noemen in de geschidenis tan de huidartsgeneeskunde.(4-8) Hierwee werd ook ingehakt op het destijus heftige debat over de wedicalisering van bulpretlening en anenlering, en de risico"s van een eenzijdig somatische benadering van gezondheidsproblemen. $(9,10)$

Terwij1 de gedragswetenschappen terecht een belangrijke rol zijn biljven spelen in de huisartsgeneeskunde, werd - gede onder invloed van epidemologische inzichten - steeds duidelijker dat ook het gedisch ambacht van de huisarts speciale andacht verdient. De in medische leerboeken en kinische lessen wervtte kennis is wooral afkomistig uit de twede lijn, war men nu eenmal genakkelijker over onderzoeksmogelijkheden kan beschikken en wax door de jaren heen een sterkere wetenschappelijke traditie is opgebouwd. Door selectiemechanismen (de buisartgerijst alleen in bepalde gevallen) en door het feit dat ziekteprocessen in het lgemeen vobr verwijzing minder ver zijn voortgeschreden ler wordt meestal pas verwezen als er een duidelijke reden voor is), heeft het vak van de hulsarts een andere wedische inhoud dan het rak van de specialist. Dit kom onder meer tot uiting in het patroon en bet beloop van de zich presenterende morbiditeit, de warde van disgnostische gegevens en de effectiviteit van behandelingen. (11) Miet alleen kowen or ganische andoeningen in de huisartspraktijk relatief minder vaak yoor, darnast alet de buisarto bij eenzelfde zidete over het algemen een ander type patienten: liet klinische beeld 19 inder witgesproken en ninder goed herkenbaar, en het beloop is in de regel guntiger. Bif gyptomen al lymfeklierwellingen, pijo op de borst, acute buikpijn, iachter in de bovenbuik en koortsconvulsies wort in de buisartspraktijk veel minder vak een ernatige diagnose of een onquntio wioktebeloop vastuesteld dan in de tweede lijin.(12-15) Dikfijl ook verkeert hat beloop in een fase warin nog veel bereikt kan worden wet relatiol wing ingijpende watregelen.

Het behoeft geen betoog dat een goed inzicht op dit gebied onisbar is voor een adequate invulling en dosering van het huisartsgeneestundig 
handelen. Daarbij kont dat de huisarts op het gehele, brede spectrum var de geneskunde ansprekbaar is Een van zijo primire taken is ow wit te waken of er uberhapt nel grake is an een medisch probleev. Inden dit het geval lijkt, woet de husarts in stat zijn alle relevante wedische terreinen te overzien en adequate diagnostische en therapeutische richtingen in te saan. De specialist kan ajn blikteld ras weet af an concentreren op het eigen segment "rooropgesteld dat: een andere functie van de hulsarts adequat wordt vervuld het wericht selecteren bij eventuele verwijuing. Renerkend voor de verhouding tussen huisarts en specialist is ook het contrast tussen de relatief beperte technische mogelijhbeden die de huisarts rechtstrechs ter beschiktino staan, en de geavaceerde technologie van het ziekenhuis.

Dit alles vragt ow een diepgande exploratie ran het geneesundige werkveld van de huisarts, met als doel het beschikbar komen wan een op zijn situatie afoestemd pakket an kennis en vardigheden. (16) overigens wil darme miet gezegd wijn dat het wedisch ambach wan de buisarts noi in 'het geheel niet is ontgonnen: onderzoek naar worbiditeitspatronen in de huisartsgeneeskunde vindt al plats sinds de jaren zestig en ook aandoeningsgericht onderzoek in de buisartspraktijk is niet nieuw. $(6,17,19,20)$ Dat het medisch vetenschappelijk onderzoek in de eerste $11 j \mathrm{n}$ in het licht van bovengenoemde inzichten een specitiek bellang heeft, wordt echter pas vrij recent in ruime kring exkend.

Inwiddels wordt er regelwatig op gewezen dat de huisartsgeneeskunde via de hermiawde andacht woor medisch-ambachtelijke uraagtellingen dreigt terug te glijden naar de somatische eenzijdigheid van het pregedragswetenschappelijke tijdperk. Hiermee wordt de vrees geuit voor een wedicalisering-nieuwe-stijl wan de eerste lijn, te meer daar veelal een strak onderzoeksprotocol wot worden gevolgd warbj wan patidnten en artsen tijdelijk een extra inspanning wordt gevraagd.

Ih ben thet ret deze kritiek niet eens. De globale, beschouwende writiek ten aazien van vedicalisering heeft hat nut bn har tije gebat; in de dagelijkse praktiju heeft de huisarts nu behoefte an wa comcreet houvast, een instrumentarium warnee beter is vast te tellen war medicalisering dreitt of aan de orde is en war juist niet. Iners, voor verandering vatbare verschijningsvormen hiervan zijn anders woeilijk herkenbaar.

Indien aan dit probleen onwoldoende andacht wordt bested, mrijgen we te waken met de medicus cynicus", die allen wit een antal impro" 
Gukture uitwegen tan kiezen, zoals:

- de medicaliseringskrtiek negeren en overgan tot de orde ran de dag:

- de hritiek asnatuen en, perlicht maar inwendig peteisterd, toch war overgaar tot de orde van de dagi

- de kitiek anvarden en vervallen tot medisch bililisae, of zoeken nar qoerces of meuve rornen van niet geếvaluect bandelen.

Produkteve oplosingen cunnem alleen worden gemonden wia een nadere verdieping hat heigen vak, en het uitwoeren van research nar de effecivlteit van diagnostisck en therapeutisch handelen bij bepalde qezondheidproblemen. Daarbij verdienen de mogelljkheden van inmovaties de aandacht, bijvoorbeld van technieken die minder invasief zijn en winder bijwerkingen en risico"s met zich meebrengen. Aldus komt men weer te weten over de vraag welke handeliogen mardevol zijn, en welke beter achterwege kunnen bljuen. Het overleg net de patient 2 al dan beter gevoed worden door relevante wedische kennis, en diens inbreng krljgt aldus een steviger ondergrond. Fet spreekt vanzelf dat hierdoor de wewarde van de integrale bendering, de preventie van somatische fixatie(8) en de gedragswetenschappelijke inbreng alleen aar beter tot hun recht komen. Het is net toevallig dat de onderzoeksijn. Preventie van somatische Fixatie van onze Nijmeegse collega's steeds zo nau verwewen is qeweest met de ontwikkling van huisartsgeneeskundige protocollen, warin obligate, facultatieve en overbodige handelingen worden onderscheiden. (21)

\section{Integrail versus gereduceerd}

Sen hemerkend mar uiteindalijt wruchtbaar spanningsweld in huisartsgeneeskundig onderzoek pordt opgeroepen door de teqenstelling tussen cnerzijds de principieel integrale benadering van de praktizerende huibarts en anderzijds de noodzakelijke beperking van het wetenschappelijk studieterrein an de reductie tot beantwoordbare vraagtellingen.

De huisarts ontwoet in zijn dagelijkse praktijk mensen met allerlei voor het zormpoces relevante imdilduele on rak unieke kenmerken. Neem bijwoorbeld de 65-jarige lleenwonende wevrouw die alleen Aov heeft, niet al te veel yan dokters en medicijuen woet hebben, on zich weleeng afvragt of het lowen nog zin beeft. Bij har wordt naar andeiding van een oriepje bij toeval een total onregeltatige pols 
ontdekt, die mogelijk al langere tijd bestat. Moet zij nu medicijou voorgeschreven krijgen voortan regelatid worden gecontroleerd?

Tervij1 de huisarts aldus te aken heeft cet een totalbeelu wain den bepalde casus, richt de onderzoeker zich op een bepald aspect van een gezondheidsprobleem dat zich bij meer mensen voordoet: in dit geval gat het he bijroorbeeld on de nog steeds llenende vration of - en zo ja, welke - medicamenteuze therapie cunstio is woor de prognose bij personen wet asymptowatisch (non-valvulair) boezentbrilleren. Voor de beantwoording van deze vraag is vergelijkend onderzoek nodit. De onderzoeker zou mevrow darom villen vragen on hieraan deel te nemen, als én van de leden van een onderzoeksgroep. Indien zyj daarin toestert, zal eerst verdere diagnostiek platsvinden. Als daruit blijkt dat zij voldoet an bepalde insluitcriteria, zal bet lot vervolgens bepalen of ze een medicijn krijgt, een "mephiddel" of in het geheel geen behandeling. Ze mag niet weten wat ze krijot en zoet haar tabletten gedurende langere tija trouw slikken. (22)

Een ander voorbeeld: een buisarts zit wet de rraag er an de hand is met een patient wet onverklaarde woeheidsklachten en duizeligheid, en overweegt en witvoerig bloedonderzoek te doen. Hij leest inmidels bij toeval in een vaktijdschrift, dat door een groep onderzoekers is vastgesteld dat dergelijke klachten over het algeween weini of geen samenhang vertonen wet uitslagen van hematologische bepalingen en leverfunctietests. $(23,24)$

Bebben in deze gevallen de complexe probleemstelling van de buisarts en het gereduceerde blikveld van de onderzoeker nog wel met elkar te maken?

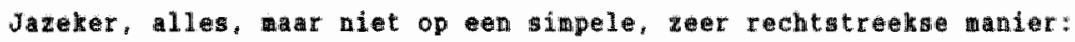

* De dialectiek die hier an de orde wordt gebeld, is hedder: enerzijds de in principe onbegrensde individu-gerichte alepgang zonder pretenties ten aanien vam algemene geldigheid, en anderzijds de reductie van de individuele warnering met veroroting van de generaliseerbaarheid.

* Om te kunnen onderzoken wot je fericht k1jker, je brandpuntafstand instellen. Niet lle lewenten kunna tegelijk scherp worden wargenomen. lat stan zinvol wordem verwerkt en geinterpreteerd. Naar mijn mening wordt de werkelijkbeid anzienlijk minder geveld angedaan als wen voor beseft en duidelijk makt dat slechts een beperkt 


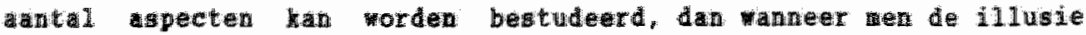

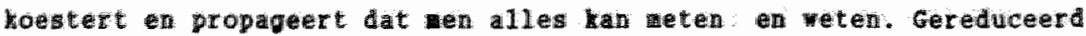
war latemict warnewen, en becheiden war gefundeerd interpreteren if een betere boumsen voor het interralle ver van de huisarts dan - zogenamd allesovattend gegevensbestand, waruit erder goed Wedoelde an goed gestolde conclusies zijn te destilleren.

- Vanzelfsprekend dient hulsartsgeneskundg onderzoek - in velke vorm dan ook vereduceerd - herkenbar en vertaabaar te blijven als elewent in het wozach we practicus. On bet in de context van de genoende roorbelden te stellen: is bet voor een rationele benadeLing, wet afmeging van de dverse optis, in het eerste geval niet cen woorwarde or kennis te beztten over de effectiviteit en de bijwerklngen van de medicamenteuze behandelingsmogelijkheden van boezemibrilleren? En, in bet tweede geval, on inzicht te bebben in de dianostische warde be te verwachten rendement van bepalde bloedonderzokingen? Is het niet nalatig hiernar gén onderzoek te doen, af onderzoek dat - bijwoorbeeld door te veel ballast - niet de bedoelde helderbeid schept?

Zowel van de praktizerende huisarts als van de buisarts-onderzoeker vergt het verfichten van of het deelnewein aan anderzoek veel toewijding en geduld. Dit geldt te weer wanneer en onderzoek gedurende langere tijd concentratie op eén deelaspect inhoudt. In sollicitatiegesprekken met adspirant-huisartmonderzoekers is de beoordelimg van het vermogen hiertoe dan ook een belangrijt onderdeel. Daarnaast moeten wij ervoor zorven dat de synthese, de invoeging wan het gereduceerde element in het mozalek van de praktijh, voor alle medewerkers duidelijk is en blijft. Behalve een goede relatie tussen onderzoek en praktijk, zullen ervaring en gerichte training op dit punt hiertoe bijaragen.

\section{Ralevantie tersus onderzoekbarheid}

In Mavolging van Miettinen zou ik willen onderscheiden: de relevantie en de onderzoekbarheid wan cen metenchappelijke vratgstelling. (25) De relevantie is bet belang van de beantwoording van de vraagstelling, bijvoorbeld voor te kwaliteit van de patientenzorg. De onderzokbarheid kent twee apecten: de validiteit en de efficientie van bet roor deze beantwoording voorgemomen onderzoek. De validiteit geeft de mate an warin bet onderzoek in stat is de geatelde via te beantwoorden. 
De efficientie drukt de perhoudin uit tussen de opbrengst thet bentwoorden van de vragstellingl en de costen wan het oncerzoek in termen

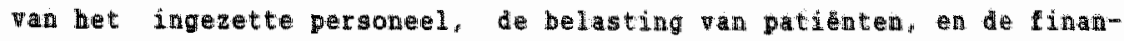
c1.

Wet problee is wu dat deze arie elementen - relerantie, validitat

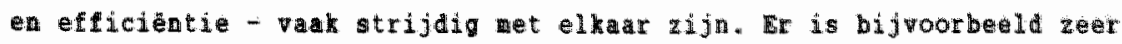
walide en eficient onderzoek, dat nawelijks relevant is. Onder het complexe veld tan de huigartsgeneeskunde is in het algemeen zeer relevant, mar is rwetsbar wat betreft validiteit en efficiente. Indien op dit terrein compromissen ononthoombat zijn, geldt ls randvoorwarde dat het uitwoeren wan het onderzoek toch en belangrijke meerwarde san informatie oplevert. Soms is devaliditeit echter zo veinig gegarandeerd, dat het ondermerp van studie niet onderaekbar moet worden geacht. Hoe relevater in zo"n gevall bet ondarmerp is, des te groter de schade die zou kunnen worden werooratat indien wen bij het toch uitvoeren wan bet onderzoek tot onjuiste conclusies kout. an bij een wellicht juiste conclusie doet zich het probleev roor dat men op grond van het onderzoek niet kan weten dat de conclusie juist is.

Daarnast bestat de mogelijhheid dat bet onderwerp wel relewant is, nar de onderzoksvrag niet. Dit doet zich onder wer voor ale bepalde activiteiten van belang zijn, on het even of ze antoonbar effectief zijn of niet. zo zou wen zich een onderzoes kunnen voorstellen nar de effectiviteit wan bet tegemoet treden van te patient als mondige ${ }^{2}$ s, of $v a n$ interdisciplinaire samenwerkin. Mls men hiervan geen gunstig effect zou kunnen antonen - bijwoorbeeld op de bloedaruk. de bloedsuiker of de gezomdheid in het algeween - il zou dan an die reden de voorkeur illen geven an en atoritaire benadering: zie zou willen afien wan samenwerking?

Gelukkig is ox in de huisartsgeeskunde genoeg onderzok te doen dat zowel relerant als valide is, en hierop dient de andacht dath ook te

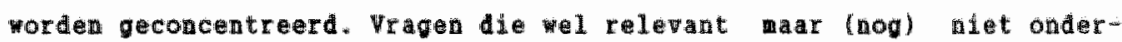
zoekbar ziju, blliven vooralsnog behoren tot het donein wat

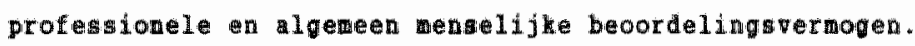

Wat betreft de eficientie is de situatie wisselend, a hankelijk ran het ondermerp ran studie. cenideld zal de efficienti wat betreft inzet van persomele en finmelele widelen bij buisartsgeneeskudig onderzoek minder quatig liggen dan bij veel klintuch en blowedisch onderzoek. Dikwijls moeten orote groepen personed worden onderzocht an 
woter anzienilju af ataiden worden overbrugd, en dit breagt hoge rel- transportwosten wet zich wee. Het systematisch opsporen van menaen met een bepalde andoening bijwoorbeeld boezemibrilleren, perifeer vat11jder of buikpathologle(26)) vergt in de buisartspraktijk vel trotere inspanningen dan in de tweede lijn; de patingten zijn in het latute geval iswers al door de buisarts geselecteerd en verwezen nareen regional klinisch centruw; war hoe dan ook veel systematische diagnostie platsvindt. Vellicht nog roter zijn de extra inspanningen bij het gestandardiseerd behandelen en vervolgen van patienten.

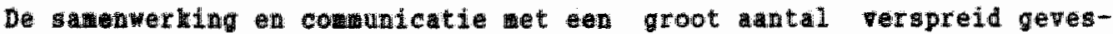
tigde wusartan, allen det bun eiven praktjkordanisatie, is op aichzell zeer boeiend, war ook erg arbeidsintensief, en hetzelfde geldt voor de verwerking van de verzadde onderzoeksegevens.

Rortom, op het punt van deficientie verdient het huisartsgeneessundig onderzoel bet nodige krediet. Dartegenover mag dan verantwoord Inhoudelijk en financieel wanagenent worden verwacht.

\section{Onderzoek en abacht}

In het voorgande werd al angestipt dat niet alle vragen die vam belang zijn voor patient en huisarts via onderzoek kunnen worden beantwoord. Patientonzorg en research zijn niet congruent. De onderzoeker wag erop orden angesproken, dat wat hij onderzoekt relevant en onderzoekbar is; de huisarts is en blijft verantwoordelijk voor de behandeling van zijn patiënten. Hoezeer de onderzoeker zich ook richt op vragstellingen die op de praktijk aansiuiten, de medicus practicus zal in de dagelijhse zorg teods zelf keuzen moeten waken, wet inachtneting van de roorkeuren en de bljzondere situatie vain de individuele wetert.

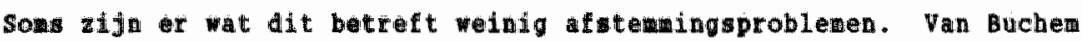
toonde bijroorbeld via cen twetal uitstekende studies aan, dat paracente in de regel achtermege kan blijwen bij de behandeling van ongecowpliceerde widenooront teking blj kinderen. $(27,28)$ zijn onderzoeksresultaten waren op zichzelf al zo overtuigend, dat publicatie ervan voldoende was on het beleid van vele huisartgen bij deze andoening op lag te veranderem. De evidentie wan de bevindingen waate een apart berad over de vertaling erwan naar de praktijk overbodig.

In andere gevallen echter, en dat zijn er talrijke, blijt de pro- 
bleemselling voor de nedicus practicus zeer complex. De onderzoeker han dan weliswar elementaire bijdragen ten behoeve wan de praktijt inbrengen, war wen noten geen gedetailleerde, algeteen geldende protocollew of standaarden worden verwacht. Metenschapelijhe kennis kas de praktjk iners nooit geheel dekken. Beide zullen tep opichte van elkar hiaten en tempoverschillen blifven vertonen, en steeds zullen er niet goed onderzoekbare of objectiverbare gebieden zijn. Bovendien, onderzoekresultaten en de daraan te verbinden conclusies kunnen in hoge rate generaliseerbar zijn, war in concrete situaties wordt de toepassing ervan gewificeerd door vele meestil niet onderzochte factoren.

Ondat er in de praktijk en positief verband is tussen onzekerheid en de woeilijheidsgrad van bolissingen (waar ween onzekerheid is, hoeven geen besluiten te vallea), is het begrijpelije dat aen juist in complexe situatios vragt on uitgewerkte richtijgnen op gezag van "de wetenschap". Men vraagt dan meestal te veel.

Dit alles houdt chter allerminst in, dat er geen vuchtbare interactie is tussen onderzok en prastijk. Integendeel, deze is op weel weer anieren an de orde dan in het kader van deze rede han worden besprow ken.

Graag geef ik een woorbeeld uit eigen buis, namelijk ons project "protocalontwikeling bartritmestoornissen". Op grond van scharse onderzoekspublicaties en wooral praktische kenmis en ervaring van huisartsen en cardiologen is een protocol geformuleerd voor het beleid met betreking tot bartritmestoornissen in de huisartspraktijk. Dit protocol werd gegoten in de vorm van een uitvoerige handleiding, warin geen Imperatieven worden aangereikt, war bouwstenen in de vorm vam kenniselementen, relevante afwegingen en keuzewonenten.(29) Ondat bij de ontwkeling van at protocol al poedig dulaeljh werd dat vel essentisle huigartsgeneeskudige tennis ontbrak, zija angluitend onderzeksprojecten gestart aarin de diagnostiache warde van anamese en lichawelijk onderzok en de effectiviteit van bepalde therapiedn morden bestudeerd. De resultaten hierwan zullen weer an huisartaen en specialisten worden voorgelegt en tot eventuele bijstelling van de handleiding leiden. Lat weI, ik spreek in dit verband niet van het "valideren" van het (gehele) protocol. Dat zou en te velonvetude en onhalbare opgave $2 i j n$, en bovendien afikennen dat ieder protocol nu eenmad ruimte lat, en mot laten, voor porsoonijike en situatief bepaalde afweginger. 
Bet verdient bif be forwleren wan protocollen uterard de voorkeur ald te richten op tratisch halbare, en niet op idealistische molllen. Daarwoor biedt onderzoek nar de ard en de walitert van het

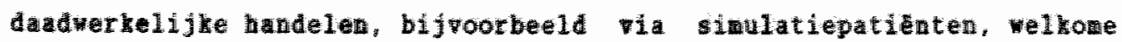
basisinformatie. ook dergelijt onderzoek wordt binnen onze oroep vericht. (30)

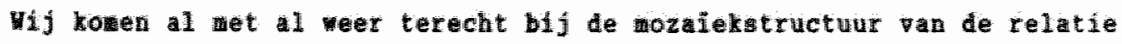
tusen de praktijh wet hulartugeneeskundig onderzoek. Het is verstadig is de onderzoeker er terreden wee $1 \mathrm{~s}$ dat hij net al zijn inspanningen, cen of enkele tukjes van bet inlegverk kan anreiken, bijwoorbeeld de varde va bepalde anamestische vragen voor de dianostiek van barteitwestoornissen. De practicus wordt geconfronteerd wet het qeheel, bijwoorbeeld bet beleid bij een patient net klachten - ile op een hartritmetoormis zouden kunnen mijzen. Hij staat dan woor de onontkombare uftaging eigen invullingen te vinden voor de witte plekken divet onderzoek openlaat. Dat behoor tot zijn vak.

Hiterbij is het naturijk goed om ervaringem te bundelen. Daardoor wordt onder neer roorkomen dat hobbyisme en toevallige casuistiek een overheersende rol gan spelen. ondersteuning kan worden gevonden in:

- intercollegiale uituisseling, bijwoorbeeld in de vorm van huisartsgeneeskundige conferenties; (31) hiermee is een evenwicht bereikbaar tussen individuele alwegingen en gemeenschappelijke of elkar corriverende kennis:

- consensusprocedures, warin met inachtmeming van de stand van kennis en de nodige beperkingen voorlopige aambevelingen worden geformuleerd. (32)

Hierdoor worden ook weer atnknopingspunten voor praktijk-relevant onderzok opgespoord. In het hader van het tweerichtiagaverkeer tusen anderzoek en praktijk dient ook de hypothesen-genererende functie van de praktzerend art de plats te krijoen die har toekont. Mar darower later meer.

\section{Wothodologische spaningavelden}

Wetenschappelijk onderzoek in de huisartsgeneeskunde kent welhast inherente wothodologische spanningsvelden, en ook deze vragen ow verdere ontwikkeling en bezinning. Ik zal er enkele bespreken. 
Bij onderzoek Dar het onderscheidend vermogen tan een symptoon of diannostische test moet men in de onderzoeksopulatie zomel de test toepassen als een standard-diagnose stellen. Ben "goudent standara bestaat in de regel niet, maar vak is een goede standard te dediniêren, zoals bet pathologisch-anatowisch preparat, het ungiogram, de uitslag van de CT-scan of het urodynawisch onderzoek.

Bij onderzoek in de huisartapraktijk is en louter ten behoewe van wetenschappelijk onderzoek toe te passen standardprocedure; zo al technisch halbaar, dan toch vaak te belastend voor de patient. Bij veel andoeningen die de husarts ziet, is de standarddianose bovendien ook winder cenduidig gedefinieerd; denkt u aar an sinusitis, migraine, het irritable bowel syndroom of surmenage. Een uitwoerig diagnostisch onderzoek lost dit probleem niet op, ondat dan nast foutnegatieve ook veel fout-positieve conclusies zullen worden getrokken.

In de praktijk moeten we dan sows genoegen nemen met het stellea van de definitieve dignose nar amleiding van het verdere beloop, eventueel angewuld met het oordeel van een panel van onafhankelijke deskundigen. (33) Het nadeel van een minder simpele, niet op én monent te meten "standaard" wordt dan gecompenseerd door do Hiniche relevantie van de gegevens over het beloop, waron het uiteindelijk gat. Dit levert overigens weer nieuwe, nader te bestuderen methodologische vraagstuken op. Dat geldt vooral voor zich langzam ontwikkelende aandoeningen warvoor niet alleen geen sirpele standaard-diagnostiek beschikbaar is, maar arbij bovendien de anvangsklacht, het daaropvolgende handelen en de diagnose na follow-up moeilijk van elkar zijn te scheiden.

Een groot deel van het erk van de huisarts bestat uit het geven van adviezen, bijwoorbeeld om af te vallen, om binnen te bijuen of het bed te houden, on het rustig an to doen, on het werk ta onderbreken of juist wiet, on te stonen of on winder koflie te arinken. Velen van ons weten wit ervaring dat dergelijke matregelen vak terk ingrijpen in het dagelljws leven, soms sterker dan een operatic. War helpen ze ook? vak is hierover niets bekend, dat wl zegoen: geevalueerd wa gedegen effectiviteitsonderzoek.

Hier ligt dus een fraas en relevant onderzoeksgebied roor de huisarts. Het beste is dan, onderzoek te doen warbij door het lot thee verqelijkbare groepen patienten worden samengestuld. De ene groep krijgt het advies en de andere niet, en na enige tijd worden de resul- 
waten wergelater.

20 ' onderzok is ectuer alleen zinwol als de patient miet weet dat

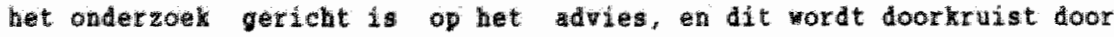
hen expliciet ow toesteming te wagen. Stelt u zich voor: went te zarar w beeft rugklachten. Dan vragt uw busarts of u wilt deelneaen an een onderzoek narar de vraag ot het advies ow at te yallen een gunstig effect heeft op rugklachter. Mls weedoet, 20 mordt verteld. wordt een enveloppe getroklen arin stat of $u$ wel of niet zo'n advies arijat. Wat zou doen als verwolgens in de niet-adviesgroep zou valen? Inderdad, voor de zekerheld toch ook war weer op uw gewicht letten. Het contrast in de rergelijking tussen beide groepen valt diarace werg.

Rorton, zolang ex expliciet en vedetallieer "informed consent" wordt vereist, is evaluatie van het effect van vele dagelijkse interventies (die ook via zelfhulp zijh te realiseren) niet goed mogelijk. Dit geldt ook voor interventies warvan de pretentie is, dat zij werken als de patident ze wet volledige overtuiging ondergat of toepast, bijyoorbeld in het kader van de "alternatieve" geneeskunde. Deze overtuiging wordt bijvoorbeeld ondermijnd, als wen weet dat en verkregen widdel ook aen placebo kan zijn.

Nat is nu ninder ethisch: de situatie laten bestan dat dagelijks vele niet op hun effect getoetste, mar soms ingrijpende, adviezen en middelen op mensen worden losgelaten, of in voorkamende gevallen zoeken nar (met voldoende varborgen onklede) alternatieven voor de expliciete, godetailleerde inforwed consent?(34) Het is in het belang van pationten onderzokers en van de samenleving als geheel dat hiervoor een duidelijk bouvast rordt gebouen in het kader van de wetgeving angande nedische experinenten. (35)

In de huigartigeneskunde is er soms sprake van "harde" uitkomsten, zod geboort en sterte. Is is en tweede, grotere, categorje uitromsten die vellswar goed gedefinieerd en in principe meetbar zijn, doch warbij het resultat altijd cen bepaalde mate van ontwerheid bevat. Dat geldt bijwoorbeeld woor bet verloop van bloeddruk, bloedbezinking, tuworgraotte of oedeen. De derde categorie - die zeker in de huisartsqeneesunde niet winder relewt is - betreft de gezondheidstoestand in de weest algewene zin des roords: hoe iewand zich voelt en wat bij (am)kan. Men spreekt hier wak van: Maldteit van leven.

Bij bet beoordelen en weten hiervan doet zich voor wat de onde 
kerkvader Augustinus opmerke ten anzien wan bet begrip tijd: "Wanmeer niemand ij pragt wat het is, weet ik bet: wanneer in het duideliji wil aken an jewand, die nij er nar vragt, weet ik het nut "( 36 ) ledereen roelt intuitief an wax het on gat war juist bijeen beschrijuing in algemene en woral weetbare begrippen is "het" nooit precies te paken. Hersteld zijn is lets ander dan weer wken ch blindheid is meer dan miet kunnen uien. Hat overblijt. is nog eerder een afdruk dan een indruk, wastgelegd in en vragenligst of op een attitudeschial.

Toch zullen wet wak wet zo"n afdruk moten doen, willen dit zeer wenlijke andachtsveld woor onderzoek ontsluiten. Dat is pok niet erg, mits beseffen dat het mar om een adruk gaat. Daarnast moeten we proberen onze afdruktechnieken te verbeteren en darin dienen we ambitieuzer te orden. Climimetrics, heot het boek warmee Feinstein ons wedici hiertoe wakkerschut. (37) Een gerichte samenverking op dit terrein wet gedragsetenschappers zal veel vooruitgang sunnen bieden.

Voor het zo goed wogelijk warmemen, meten en veergeven van een segment van de werkelijkheid is wel cen voormarde, dat dit ook van belang is voor bet gezondheidsprobleen dat bestudeerd wordt. Bij onderzoek matr bet beloop van lage rugklachten in de huisartspraktijk is seride CT-scanning irrelevant, en de welding dat lemand pijn heeft. is vak belangrijker dan de score op een pijnschal. Rortom meet datgene war het or gaat, doe dat zo goed mogelijk en besef dat het een afdruk is. Ook een hologram is lets anders dan het geholografeerde object. Besef ook dat de beoordeling van belevingsaspecten sterk afhankelijk is van de wijze warop wragen worden gesteld, van het moment beoordeling en van owgevingsinuloeden. $(38,39)$

Er is cen gen klassieke la actuele digcusie gande over de vraag of de meest betroumare gegevens over het woorkomen van klachten of ziekter in de huisartspraktijk verkregen worden via een volledige contactreajstratie (warbij gegevens van in principe leder patient-artis contact worden astgelegd), dan wel wia onderzok dat zich beperkt tot de klacht of ziekte varin aen gezteresser is.

De voorstanders van bet eerste voeren andat bij fixatie op én of enkele problemen de buisartisen overdreven diep qraven en dus ook owerdreven wel, wak hinsch itrelewante getallen vinden. Tevens wordt door hen het ietwat tegengestelde argument genoend, dat wen bij 
wen gerichte arapak het gevar loopt vel gevalien te alsseb de huidarts ord hiet gedwongen steeds zijn conclusies te classificeren. en zal dus in slap sukeren. Dit nog afgezien wan het feit dat een volledige registrate gegevens oplevert over bet gebele nosologische spectrux.

De anhanger an een getlchte appak stellen, dat alleen darmee voldoende diepang et toetsing an dagnostische criteria wan worden bereit, en dat by en "volledige" registratie veel van de voor de wrabselino relenante vewallen onder andere "codes" geregistreerd zullen worden. 20 munen veel patienten met boezenfibilleren bij angetoond organisch lijden zijo weggeboekt onder ischemische hartziekten, herwill patienten met lyafeklierzwelingen wak terechtromen in de categorieen verkoudheid of kelontsteking. Onderzoek gebaseerd op een 1 dus "uitgeklede" diagmosegroeg gat dus uit van een zeer geselecteerd seguent van de patientenpopulati. Hiervoor is achteraf niet bevredigend te corrigeren.

Welke optie de beste is, hangt af ran doel en ragstelling van de studie, bet type andoening warop men zich richt, en de beschikbare menskroht en middelen.

In Nastricht krljoen beide opties hun plaats.

Nan het arien de Vakgroep Medische Informatica en statistiek en het Medisch $\mathrm{En}$ Matschappelijt Informatie Centru (MEMTC) opgezette Registratienet luisartsprakijken doen thans ruim 25 huisartsen mee. Van iedere ingeschreven patient zal de huisarts een beperkte set van persoonsgegevens bljhoudon ot onder andere leeftjd, geslacht, burgerlijke stat, verzekeringsvor en woonverband. Tevens wordt er een overzicht wan alle relevante bij de huisart bekende gezondheidsproblemen opgebouwd, getoetst aan roor de huigarts hanteerbare diagnos-

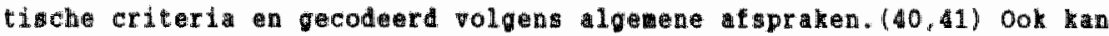
per patient bet adicijngebruik worden vastolegd. Het geheel wordt bijgehouden viaktijkcomputers die zijn angesloten op een geanoniwitserd, central bestand.

Lerdoor lont wen longludinal en up-to-date stcekproefbestand ter beschikking dat betrehing heeft op circa 60.000 ingeschreven personen, nast een goed overacht wat het worbiteitspatroon in deze populatie. Hjdrovend en wak inadequat gezoek in kartenbakken wordt daarme pratisch overbodio. Er kunnen snel steekproeven worden getrokken, en onderzooks - en controlegroepen samgesteld. Teveas zal wonitoring van gebruit en bijwerkingen van geneesmiddelen beter mogelijk zijn. Bij dit 
alies knnen wij op veel puten terugullen op de expertise val onze collega"s elders in den lande. $(42,4)$

In de tweede plats zijn er gerichte, feer diepgravende onderzoensprojecten, die in de regel speciale inspaningen en een aparte organsatie vergen. Voor cen bepalde vrabstelling wot iners weestal systewatischer en veer in detail worden wargenomen dan routinematig Lan worden vatgelegd. We1 ligt bet poor de hand da steeds weer van deze projecten geent zullen kunnen worden op de infrastructur van het registrationet. (43)

Door de toenemende belangstelling voor praktijkautomatisering en de opbouw ran grote huisartsgeneeskundige registmtiebestanden is het inmiddels steeds belangrijker geworden dat de sterke en zwake punten hiervan worden geanalyseerd. $\mathrm{Er}$ is dan ook behoefte an en methodologisch handboek warin beschreven worden:

- de mogelijkheden, de indicaties en contra-indicaties ran het gebruik vall deze bestanden:

- de afwegingen rond de keuze van het onderzoeksontwerp;

- praktische aanijzingen roor het gebruik.

Daarnaast moeten wij ons hoecen voor overenthousinst modernisme. De inhoudelijte en technische problemen rond het opzetten, bijhouden en adequat gebruiken van zo"n gecomputeriseerd teekproefkader zullen aanhoudend zorg vraged en soms baren.

Huisartsen nemen dagelijks vele tientallen beslissingen in het xader wan het zordproces. Vele zijn niet weer te herkennen doordat ze zijn opgegaan in routineprocedures. Andere worden wel "ervaren" en gan, hast per definitie, ut van onzekerheden: juist war onzekerheid is. moeten imers knopen worden doorgehakt.

on artsen te helpen bij het optimaliseren van het hierbij te verwachten resultat en het zo kleir woglijk when wan de kans op ongunstige gevolgen, is een antal techieken ontwikell, warvan vel wot verwacht. Met name de nedische besldekunde heeft turore gemakt. Er zijn inderdad diverse nuttige functies dio de besliskunde kan bebben, aet name:

- bet overzichtelijt tructureren van wediche beslissingen in oen beslisboow:

- het daaraan nopelen tan wen problecmanalyse, ultgaande van kansen en warden op basis warqan en optimale strategie zou kunnen worden gewonden: 
- bet bierdoor cheppen van een basis voor consensus es rationele beslutituoring:

- het ldentidicen wan prioriteiten voor gezondheidszorgonderzoek. (45) Er zijn yele opmerkingen te maken over de geschiktheid en de beperkingen wa de adsche besiskude poor de huisartsgeneesumde. (46,4) Ve kunen hier slechts kort zijn. De rechtstreekse bruikbarheid in de dagelijhe patientenzor is wijns inziens vooralsnog gering, zeker bij de zo frequent toorkowende klachten warbaj niet geakkelijk enkele goed onchreven diagnostidche hypothesen kunnen waton opgesteld. (4) op dit monent is wer te verwahten van de weer indirecte effecten van de besiskunde, als instrument voor onderwijs, mascholing, intercolleqiale toetsing. de evaluatie van de stand van kenis en de constructie wan medische leerboeken. Daarbij ligk de nadruk niet zozeer op naukeurige en cenduidige Baysianse hwamticering fwarvoor wak te veel gegevens ontbreken en subjectieve warden te unik zijn), mar op explicitering, structurering en fasering wa het besluitvoringsproces.

Voort zijn eenvoudige epidemiologische en besliskundige concepten bij uitstek geschilt ow de identiteit van de huisarts en diens zeeffunctie ten opzichte van de tweede lijn te verhelderen. Daarbij gat het onder meer am de eerder wenoende betekenis wan gelectie door middel van verwijing voor het onderscheidend vermogen van diagnostiek, voor de fectiviteit van behandelingen en prognose. ook wordt woor deze concepten onderstreept hoezeer juist huisartsen woeted werken met onzekerheden. Als zij dit niet kumen vervallen zij tot ver doorgevoerde defensieve geneeskunde, veelal tot schade van de patient. De huisarts, die woet doorzeilen tussen overmatig aedisch handelen en het missen van relevante diagnosen, kan daarom wet recht de evenwichtshunstenar in de geneeskunde worden genoend. (16)

\section{Relatie wet huisurten}

Crebolder is in zijo recente oratie uitvoerig ingegan op de samenwerkav tusen de uniwersteit en de diverse eerstelijnsisciplines. (49) stat u wij toe dat ik wij hier beperk tot de buisarts.

wen conditio sine qua non roor - zowel uitworbar als relevant buisartageneeskundig onderzoek is een goede relatie wet de huisartsen in de regio. De afolopen jaren zijn gekenmerkt door een proces van woderzijds leren en samen opbouwen. Dat heeft al vele resultaten 
opgeleverd. Mar er is nog vel meer nogelijk in deza in diverse opzichten unieke regio, en de erwaringen de tuidige ontwikglingen rechtvaardigen optimiswe poor de toekonst. Van groot belang hiecbij is een gelijkwardige relatie tussen de partners, wet erkening wan elkaars rol en bekwameden. In het besef dat op dit gebied een continu leerproces platsvindt, meen ik dat vij ook hier op de goede weg cijn. Het is juist daro interessant on de gehanteerde terminologie ens onder de loupe te memen.

Destijes beb it aij bijwoorbeld verzet tegen de thans toch ingeburgerde ter "academigering van de eerste lijn". Deze uitdrukxing roept de suggestie op dat de universitedt het op de veest punten beter weet en zich wit dien hoofde geroepen woelt het niveau wan het eerstelijnsveld te verheffen. Men vergeet hierbij dat juist de universitaire nedische wetenschap de buisartsgeneeskunde lang genegeerd heeft. Pas lat in de jaren zestig verden, na jarenlange inspanningen van de huisartsen zeli, de eerste leerstoelen in de huisartsgeneskunde ingesteld. Ir is dan ook veel voor te zeggen om het met mademisering" bedoelde proees aan te duiden wet. "vernatschappelijking van de academie" . (50)

In beide gevallen drukt wen zich echter ten onrechte uit in termen Tan eenrichtingsverkeer. Het zou dan ook goed zijn als ex meer evenvichtige anduiding zou worden gekozen. Onze tal is daarvoor rijk genoeg.

Een andere an en rondow de universitelt veel gehoorde hwalificatie warmee ik oeite heb, is die van de "perifere" huisarts. Deze benawing impliceert dat ex ten winste twee soorten huisartsen zijn: perifere niet-perifere (ot "centrale").

Ruimtelijk han dit niet bedoeld zijn. He kennen imers "perifere" huisartben die lak nast het faculteitsgebour zijn gevestod, on nietperifere bujartsen in Venlo. Hoe is het da bedoeld? wen han er allerled. val onzakelijke inulingen an geven. Het gevar bestaat dan cat er cen vaarde-oordeel insluipt, niet aldeen ten opzichte van wet weld, mar ook bij de buisartisen zell, geinternaliseerd en sow zelfvergoelijkend. Wie heeft noolt horen zegoen" "wat weet een perifere huisarts bier nu val ?" Het lijkt ax welens op dat het woord "perifeer" de tegenpool wordt van "geacademiseerd".

Lat ons liever zakelijk blijven: er zijn hulsartsen die wet de universteit een contract (net bijbehoread takenpaket) hebben, en huisartaen die dat niet hebben. Allen zijn vanuit de eigen invalshork 
qebat en betrokhen bij een verbetering van de beropsutoefening en

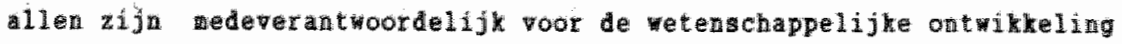

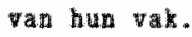

In dit verband wil ik ool afrekenen wet bet woord "waterdragers". Dit word lat hier niet op patistuten die gevend zijn zich wet een llesje verse urine nar de doter te poeden; bee, deze sanduidino treft de an onderzoek medewerkende hularts, die zich welens aldus beschoud

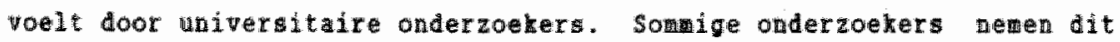
woord inderdad at en toe in de mond, warschijnlijk ow gen ondujdelijhkeid te laten bestan over hoe zij te verdeling van taken en verautwootdelijkheden rond hun project zien.

Het is evident dat oo in dit geval misplatste warde-aspecten Areigen binnen te dringen, die zich roor langere tijd hunnen watzetten. Het is darrom goed hier de aadacht te vestigen op de grote inzet un vardigheid die vereist zijn ow temidan van de drukke praktijkbelommeringen an durende langere tijd onderzoeksgegevens van hoge kwalit te verzatelen. Meestal woeten gestandardiseerde procedures worden gevolgd die at en toe tija, en voortdurend concentratie vergen. reven woet de deelnewende huibarts bereid en in staat zijn om iets extra's van de patient te vragen. zoals het invulen van een vragenlijet, het ondergaan van een special onderzoek of het deelnemen an een lotingsprocedure. Dit alles raagt training en ervaring en en zeer goede relatie met de patienten. Ook een frequent en open contact met de onderzoekers is een voorwarde.

Universitaire medewerkers die onderzoek in de buisartspraktjk willea doen, dienen dit alles te beseffen. Zij zouden moeten overwegen ter voorbereiding van hun project en onderzoeksstage ter platse te lopen. let if in dit gerband dudelijt dat huisarts-onderzoekers, die in beige betrokken exsituaties ingerijd en wetief ijn, een enorme vergterking van de amenwerking tussen universiteit en veld belichaten.

In het voorgande is in felte de meest bekende vor wan onderzoekssaonering tusmen universiteit an praktizerende huisartsen benoend. napelijh die op het gebied van de geqevensuerzaneling. Een tweede vori is dialoog over de onderzoeksonzen en -rganigatie tussen onderzoekars an delnewende huisartsen. zelfs per pratijh kunnen specifleke oplossingen gewenst zijn. Als wen deze dialoog in de voorbereidingstase van aen onderzoek overslat, is de kan wan slagen gering. Achterat inhalen at in deze fase is verzuim, is zelden ogelijk.

De derde - tot nu to wel minst ontwikelde - vorm van samenwerking 


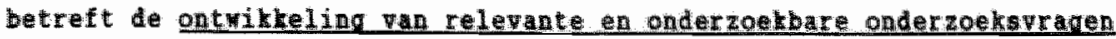
en hroathesen. Vorderingen juist op dit gebied zulien wijns inziens in de kowende 10 jaar ran beslissende betekenis aijn voor de huisartsgeneskundige wetenschap. De neeste wedische kennis die rij bezten heett iners zijn wortels in praktjkervaring en kinische warnewing. of het nu gat on ijzertherapie, de preventie van kaamvroumentoorts, digitalisatie, de gevaren van het roken of de ontdeking van MIDS. Pas nar anleiding van de erste alerto warnemingen en beordeling hiervan in het licht van hetgeen al bekend is, komt de methodoloon in het weweer on nadere toetsing te verrichten. Van uitwiseling en uitieping tan ervaringen via huisatsgeneeskundige conterenties(31) an in dit verband veel worden verwacht en huisarts-onderzoekers kunnen ook hierbij en katalyserende functie vervullen. Gezamenlijke. meer systematische inspaning en vardigheidsontrikkeling op dit terrein zijn nodig. Hierdoor kan worden voorkowen dat de beheerders van een zo rijk war weinig ontgonnen onderzoeksveld zich voor de poorten van steeds dezelfde subsidiegevers verdringen cond steeds dezelfde thewa's. Tevens wordt aldus vermeden dat het wethodologische aspect. hoe belangrijk ook, een te centrale rol gat spelen: wat is imers het. perspectief wan een wethode zonder reletante inhoud?

De lastste vorm van samenuerking houd in dat, nast de special daartoe angestelde en opgeleide huigarts-onderzoekers, andere prakti zerende huisartsen zelf een onderzoek leiden met ondersteuning van de universiteit. Aan onze nog jonge instelling kow dit nu op gang. in navolging van vooral het Nijweegs universitair Huisartsen Instituut. Lang niet iedere huisarts zal hieraan toekomen. Men moet over voldoende tijd beschikken en zich de nodige extra deskundigheid eigen waken. De universiteit kan faciliterend optreden door inhoudelijke, praktische en wethodologische steun te bieden en te bewiddelen bij subsidieverwerving. Een speciale bijarage zou kunnen kowen van het Post Academisel onderwijs Geneedkumde: op basis van - weelal reeds ontwikeld - cursus-

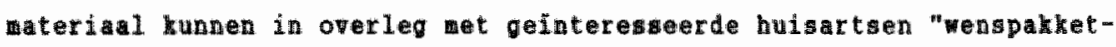
ten" voor onderzoeksscholing worden samengesteld.

Ik 11 in dit kader nog een kanttekeming when: om diepgang en kwaliteit te bereizen woeten de unitersiteit en, fortiori, de vakgroepen zich concentreren op en beperkt antal onderzoeksthema. Deze concentratle kan, zeker bij niet an de universiteit verkawe personen. owerkomen als en keurijj, dat alle fradie voornemeng angande 


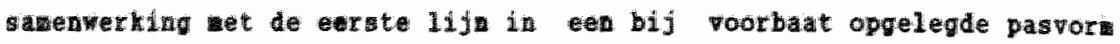
perst. Wooral ten anzien van ex pkgroeg ds de onze, die sabenerkt wet op on breed terrein actief veld. areigt dit gevar. ook het viden van een vruchtbare synthese wanut dit spanoingswell is een

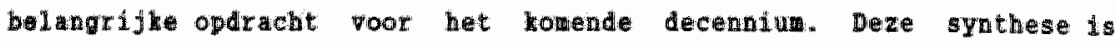
nodio, wet alleen terwille van de goede werthoudingen en het waraken

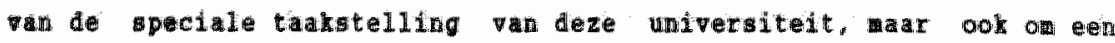
weer principiele reden: een buisartsgeneskundig onderzoeksprograna kan alien vital en relevant bijven als het een inhoudelijke relatie hest wet de ve ontmikelingen in de buigartsgeneesundige wereld. Zen van de rolijhbeden hiertoe is het verruiben van de consultatieve en ondersteunende functie tan de universiteit tev behoeve van huisartsen. Dit behoort tot de doelstellingen van bet recent door de medische ficulteit opgerichte cobranatieburo Rerste Lijn (CEL).

\section{Sarenwerting in elgen buis}

Mled a door de ard van de te bestuderen gezondheidsproblewen liggen er evidente anknoplingspunten voor de onderzoeksamenterking tussen eerste lijn, (poli) ninische geneeskunde, bionedische en sociale wetenschappen. Het i dan zaak dat er cen structuur bestaat on tot deze samenwerking te komen. Ik men dat dit thans an de Rijksuniversiteit Liburg ruimschoots bet geval is. Op effectieve wijze kan een functionele en produktieve samenwerking worden opgebound. Dit is erg belang rijk. De extramurale gerreeskunde heeft rel hat eigen blikveld en verkinhoud, war ist toch de secifieke disch-technische, medischbiologische en social-wetenschappelijke diepgan van de zojuist venoende partners. Mlinische biomedische onderzoekers kunmen, van wur kant, de relevantie van hum werk verbreden dook bijaragen te loveren an de veroroting tan de sennis over dianostiek, beloop. therapile oor aken van andoeningen die relatief zelden de tweede lijn bereiken, of de vooral doen in (te) vergevorderde gtadia. De inbreng va gedragswetconschpers tan, nast en vanut de reeds bewandelde wegen, nuteume perspectieven openen. Hierbij. moet onder meer worden gedacht an het onderzoek op het gebied van de swaliteit van de huisartsgeneeshundige zorg, wet medisch probleem-oplossen, de achtergronden van a distostie bij diverse klachtenpatronen en de ontwikeling wan geschikte aten en weetprocedures voor gezonaheidsbe- 
leving. Ilet is verheugend dat an onze universiteit invidels op wrijwel al deze terreinen sawemerkingsverbanden zijn ontwikeld, en dat de vakgroep Euisartageneesunde hieraan for bijdraat.

Belangwektend is voorts de sanenwerking tussen de ralkgbteden hulsartsgeneeskunde en medische informatica. Hierbij kunen ulevwe bronnen worden angeboord op het gebied van de kwaliteitsberalim en de ondersteuning pan aedische besluitrorming, en als centrale informatiedrager in de gezondbeldszorg krijgt de huisarts ongekende mogelijkheden.

speciale vermelding verdient het Diagnostisch coordinerend centrun wanuit het hcademish Ziekenhuis Mastricht. Als reolonal overleg- en scholingsplatfor poor huisartsen en specilisten is het oen voorbeeld voor andere platsen. In het licht van nieuwe inzichten en onderzoeksresultaten worden werkafspraken gemakt en bewakt, gericht op een rationeel gebruik van medische voorzieningen. (51) bit instituut heeft naar wijn wening de potentie ow uit te groeien tot een internationai centrum roor health care research op het orensvlak ran cerste en tweede $11 j n$. De basale ingredienten ow hiertoe te komen aijn reeds anwezio. zeker nu in de kliniek en vanuit de vakgroep spideniologle in hoog tempo an de klinisch-epidemiologische benadering wordt vormgegeven.

9. Onderzoek en onderwija in de huisartsgeneeskunde

Op de universiteiten dienen wetenschappelijk onderzoek en onderwijs elkar intensief te ontmoten, en in onderlinge wisselwerking bij te dragen aan de vorming van de wedisch student tot een zelfstandi en kritisch beroepisbeofenaar. Nat ait betreft bestaan or in het basiscurriculum en ook darna diverse wogelijkheden en verplichtingen, die bovendien verder ontwihleld zullen worden.

veel wa worden verwackt van de imsiddel gestarte meerjarige bo roepaopleiding tot huisart, warin de ankomende beroepsbeoetenar neer dan voorhen - een basale wetenschappelijke scholing kijgt. De huisarts van straks zal dardoor beter lif tat zijn het vak op kritische wijze blj te houden en op verantwoorde wijze bijdragen to leveren aan onderzoek.

Wasst deze algewene wetenschappelijke scholling voor alle anstande buisartBen zal er beboefte blijven an een speciale opleiding voor huisarts-onderzoekers die zowel praktizeren als leiding veven an onderzoek. Het is verheugend dat, wede gezien de positieve ervaringen 
tot wit toe, an de pocrararden hiervoor op diverse platsen tegenoet gekowen ordt.

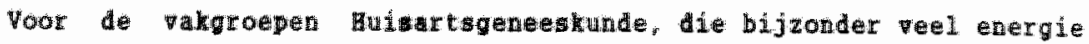

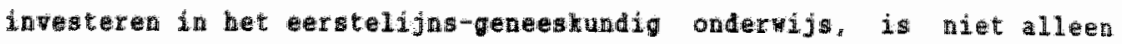

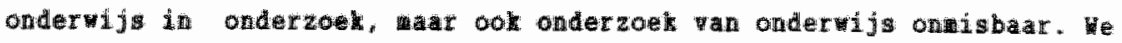

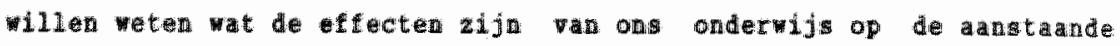

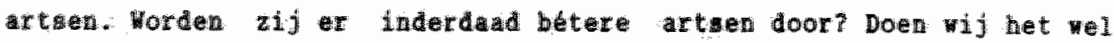
woed genoef of woten bet anders anpakken? bij het beantwoorden var

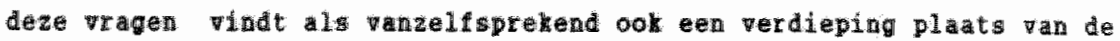
Renuls over de wjze warop artaen medische problenen oplossen (52). A. we darover wet weten, zijn opleiding en bijoholing iners weel beter te suren.

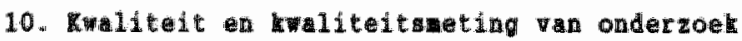

Het Is god en vanzelsprekend dat er ten anzien van wetenschappelijk onderzoen waliteitsberiking platsvindt en dat daran consequenties worden verbonden. In pritude is er imers geen verschil wet andere activiteiter arbij grote verantwoordelijkheden worden gedragen, zods de prat sche gezondheidsoro.

De indudels gegroeide beordelingspratijk, warbij voor of witsluttend wort afgegan op output in de worm yn internationale publicaties, levert de Wederlandse huisartsgeneskunde echter de nodige problemen op. Hoe ond baar internationale uitwisseling en toetsing ook is, de vaderlandse buisartsgeneeskunde ma het nationale, van goede tijaschriften voorziene, wetenschappelijhe publicatieircuit geensins verwarlozen. De mer dan zesduizend aruk bezette beroepsbeoefenaren woeten het pooral hebber wan dit circuit. Het zou uitermate preend zijn a. Nederiands hulartsen resultaten van Mederlands buisartsgeneesundio ondergek niet of wleen in voor hen nawelijks toegankelijke tijdschriften zouden hunned lezen. Dubbelpublicaties fowel internationaw al Heterlandsy zijn in een artal gevallen mogelijk en moeten bevorderd worden, war zij brengen wel extra tijasbesteding met zich new. Sow ool is het risico dat een international tijdschrift $20^{\circ}$ m dubbelpublicatie niet accepteert, of lange tijo ophoudt totdat de eigen vert is verschenen. Darbij kom, dat roor de Nederlandse huisarts relevant onderwok door diens specifleke situatie lang niet altijd Interesiant is voor een international forum Moeten we dit type 
bljibar "niet-tellend" onderzoen dan war niet veer doen, zonder bns

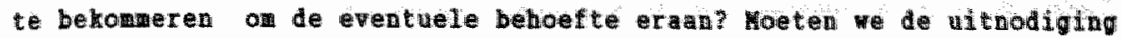
ow te publiceren in een Nederlandstalig tijdschrift - vroeger nog als een hele eer beschoum - nu ervaren als een schadelijke last war je onderuit noet zien te komen Dit zou kumen gan betekenen, dat de vabuladen van de Nederlandse huisartsen net tweederangs iateriaal wowen te zitten, terwijl de universitare instuten zich gan richien op verre warken.

En dan nog hebben deze instituten war weinio greep op de internationale hitparade voor onderzokers. On een voorbeeld te noemen: de impactictor van het meest gerenoweerte internationale huisartageneegrundige tijdschrift, het Journal of the Royal college of General Practitioners, is 20 keer 20 latio als die van een blad als The cell.

Tortow, we woten voorkomen dat bet wadewisch bezig zijn geleid gat worden door het dagelijks ter hand nemen van de beursberichten over de impactkoersen, om te zien op like bladen we nu het best kunnen mikken of hoe goed of slecht onze collega's het doen. Het is evident dat at: niets weer te waken zou hebben wet en wetenschappelijk kilatat dat is gericht op uitdieping wan het eigen vakgebied en uitwisseling hierover wet andere betrokkenen. Feedback dient inhoudelijh te zijn, en zich niet te beperten tot behalde scores. On nog mar niet te spreken ran de nadelige gevolgen van bet risicovermijdend gedrag dat kan ontstan: woeilijk, arbeidsintensief en grootschalig onderzoek dat pas op langere termijn resultaten oplevert wordt steeds winder antrekkelijk, hoewel juist dit type onderzoek in de huisartsgeneeskunde raak noodzakelijk is.

Het is verheugend, dat de geschetste problematiek in steeds bredere kring wordt ingezien, en at en reêle differentiatie in beoordelingsnormen thans besprekbar is. De vakgrowen buisartsoneaskude zullen op dit gebied creatieve bijdragen leveren, en voorstilen ligon reds war.

\section{S10t}

Terwil wijn opdracht vooral ligt op het gebied van bet onderzoes in de huisartsgeneesunde, voel ik ij medeverantwoordelijk poor het vakgebied als geheel. Daarom xan ik het miet nalaten nog enkele woorden te zeggen over een ontwikting die mi crnstige zorgen bart. Ik doiel 
Heree op de 1 plicaties van het mabinetsstandpurt inzake het advies

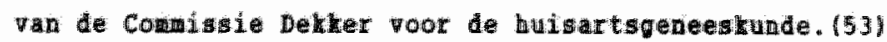

Er zlji zeker goete elenenten in de habinetsnota, zoals de anandat woot kwliteltsbewaking en -bevordering, substitutie wan twede nar

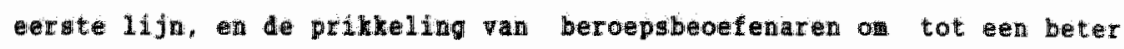
"produt" te howeh. De kibinetsvoornewens verraden evenul een beleid,

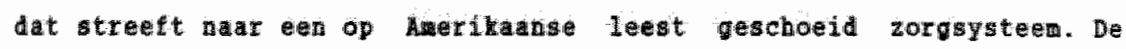

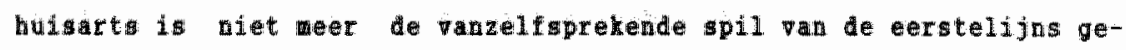
zondlieldsorg, en arar nodid doorwermijzer. Gesproken wordt over een functegerichte benadering varin en "vel winder stribte relatie zal ontstan tussen instelling/beroepsbeofenar enerzijus en type zorguerlening anderzijus".

Howel concretidering goedeels ontbrekt; is duidelijk dat veel wordt overgelaten an het wije spel der matsehapelijke en professionele krachten en de verhouding tussen vraag en anbod. Bij lezing van ae kabinetsnota kam bij mij een beeld op van concurrerende zorgverleners, doolhowen woor gebrulkers, desintegratie wan integraie zorg, van survival of the fittest. De goede kanten van de not.a raken hierdoor in. ae schaduw

Wat betreft de huisarts ach ik in $1 k$ geval de twe in het begin wan deze rede genoende, elkar arnwullende kernfuncties essentieel en onverwangbaiar:

* Diens generalisme, ls algemeen toegankelijk hulpverlener die in staat is tot een eerste (en weestal afdoende) professionele beoordeling behandeling wan de problematiek. Dit, met inachtneming van de nu cenmal lang niet atijd van elkar te onderscheiden somatische en paychosociale aspecten. Dit generalisme verschaft de huisarts bovenden een zeer geschitte basis voor continuiteit van zorg en begeleiding vas chronische patianten. Ophefing, opdeling of facultatief wellen van deze functio bekwabeid zal een enorme kapitals vernituging en een woorlopig onber telbare ansiag betekenen op het basale gedelte wan de medische bulprerlening. Ix acht deze generam listische functio, juist in dere tijd van toememende differentiatie w complexiteit, zo essentieel dat zij daar war zij conflicteert met substitutic dient te prevaleren.

- De zeefunctie van de huisarts, die alleen kan bestan op een genera1istiche ondergrond. Wet creeren wan de mogelijkheid dat gebruikers deze zeef op eigen houtje passeren, zal veel ineficientie, dwalwegen en schade te weeg brengen. 
Nar het systeen piet goed werkt - en op een antal punter ls dat zeker zo - kan wen het verbeteren net behoud van deze functies. Het

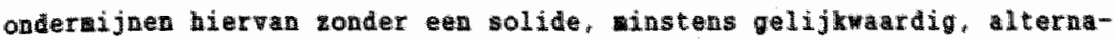
tief is mar aijn mening niet verantwoord, en zal lejden tot beschadiging van een gezondheidszorgystem warop in we landen terecht jalloers is.

\section{Dentmoord}

Het dant an de collegae $\mathbf{H}$. Crebolder, $C$. de Geus, T. Lemmens $F$. Sturaans roor bet kritisch doornemen van de concept-tekst van deze rede. 
Witeratude

1. Huskens LIJ.

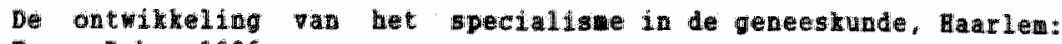
Erver Bohti, 1906.

2. Buma JT.

De husirts en zijn patient. Grondsiagen van bet medisch denken en Hadelen. haterdan: Albert de Lange, 1950.

3. Ironien.

Het Woudshoteurapport. Utrecht: Hederlands Huisartsen Genootschap. 1959 .

4. Crebolder IIIS.

onderzokingen rond aen gezondbeidscentru [Dissertatie]. Mijuegen: Aatholieke Universiteit ajnegen, 1977.

5. Holten-Vriesem J, Tompot $C_{\text {, }}$ van Aalderen $B$, a.

"Hethodisch werken". Over een algewene methode van hulpverlenimg en de opbour van functionele relatie toegespitst op de huisartsprakijk. Huisarts en wetenschap 1978: 21: 322-35.

6. Huygen PJa.

Yamily wicine. The medical life history of familes. Nijmegen: Deker \& Van de Vegt, 1978.

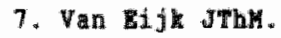

Levensgebeurtenissen en zierten [Dissertatie]. Mijmegen: Katholieke universiteit Hijegen, 1979.

8. Grol RPTH, red.

Huisarten sotische fixatie. Theorie en praktijk van de preventie won somache ixatie. Utrecht: Bohr, Scheltewa Holkewa, 1983.

9. Zola IK.

Hedicine as an institution of social control. The socialogical Reviev 1972:20: 487-509.

10. IIIich ID.

Hedical newesis, 1975. The expropriation of health, London: Boyars, 1975.

11. Rnottnerus Jih.

The effects of disease verification and referral on the relationship between symptoms and diseases. Medical Decision Mating 1987; 7: $139-48$.

12. Miliamson $\mathrm{HA}$.

Lywadenopathy in family practice: descriptive study of 249 cases. The Jourmal of Paily Practice 1985; 20: 49-52.

13. Kottnerus JH, Mbens $\mathrm{G}$, Govaert ThWB, De cous CA.

Rilachten op do borst, omgan wet onzeherheden. Huisarts en wetenschap. 1985; $28: 159-64$.

14. Dowbal T ae.

Transporting databawk of medical inforwation fow one location to another. Etective Health Care 1983; 1 : 155-62.

15. EIlemberg JB. Melson KB.

Sample selection and the natural history of diseases. JHMA 1980; 243: $1337-40$.

16. Hottnerus JA.

Metidehe besiuitvorwino: Terschillen tussen huisarts en specia1itt. Aijblijven 1987; $3: 30-46$.

17. Hodglin $\mathrm{t}$.

Towards earlier diagnosis: a family doctor" approach. Edinburgh:

Church111 Livingstone, 1963. 
18. O11 ians AP.

Korbiditeit in de buisartspratijk, Leiden: Stenfert Rroese, 1969.

19. Lamberts

De vorbiditeitsanalyse-1972 tan de groepspratijt ondoord. Fen nieume ordening van ziekte en probleengedrag in de buisartsgeneskunde. Wuisarts en Netenschap 1974; 17 : $455-73$; Huisarts en Menschap 1975; 18: 7-39, 61-72.

20. Huyeren FJA.

Lobaire pneunomie als besmettelijke riokte [Dissertatid. Utrecht: Rijksuniversiteit Utrecht, 1948 .

21. Grol R, Hesker P, red.

Euisarts en onderlinge toetsing. Utrecht: Bunge, 1986.

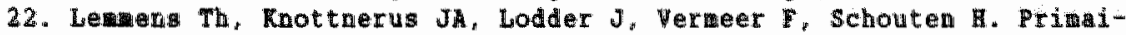
re preventie van arteriele trombo embolische processem bij nonRalvulair atriu fibrilleren. Studieprotocol, Rijksuniversiteit Liburg, Mastricht 1988.

23. Rnottnerus JA, Knipschild PG, Versch JHJ Wan, sijstermans AHJ. Unexplained fatigue and heqoglobin. primary care study. Canadian Family Puysician 1986; 32: 1601-4.

24. Rerkhof PD, Rnottnerus JA, Dinant GJ.

Levertests in de huisartsprantijk; te bevestiging of ook ter uitsluiting van leverpathologie? The Practitioner 1987; 4: $825-33$; The Practitioner 1988; 5: 157-9.

25. Miettinen OSM.

Lecture on form design in epidemiologic research, Austerdaw 11 february 1988.

26. Ter illustratie hiervan kunnen dienen de door onderzokers van onze vakgroep ontwkelde onderzoeksprotocallen net betrekking tot de diagnostiek en interventie van perifeer arterieel obstructief vatulijden; diagnostiek van hartritmestoornissen; therapie bij boezerfibrilleren; diagnostiek niet-acute buiklachten. IOp anvage verkrijgbar).

27. Bucher FL van, Dunk JHK, Van "t Hof $\mathrm{Kh}$.

Acute otitis media: paracentese, antibiotica of geen ran beide. Ned Tijuschr Geneesh 1982; 126: 462 7.

28. Buchem Fu Van, Peeters MF, Van't Hof MA.

Aanpasing van therapie an het verloop van otitis media. Hed Tijdschr Geneesk 1985; 129: 1093-9.

29. Castermans GAHM, Gorgels APH et a1.

Manull hartritwestoornissen. Richtijnen voor de praktische anpak voor de buisarts. Projectoroep Hartritaestoornissen RL, Haastricht 1988.

30. Rethans $J$, Boven CPA wan.

simulated patients in general practice. Alfferent look the consultation. Br Hed J 1987; $294: 9-12$.

31. Huygen Th.

Huisartsqeneeskundige conferenties. Huisarts en Wetenschap 1980;

$23: 13-5$.

32. Everdingem JJE van.

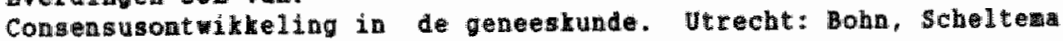

Holkesa, 1988 .

33. Feinstein $\mathrm{MR}$.

Clinical epidemiology. The architecture of cldical research. Philadelphia: Saunders, 1985. 
34. Rotrierus JA, Vet BCW ae.

itfectiteltowderzoek to de buisarspratijk. 3. Algemene opmerHingen over gerandowiserd interventie-onderzoes in de huisart-

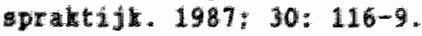

35. Whot trierus JA.

Dhale stellingen wet betreking tot "inforwed consent". utrecht: Labdelifi bureau coôrdinatie le en ze $11 j \mathrm{a} .1988$.

36. Muse1 B.

Geschienis der resterse filosolie. Ge dr. Ratrijk an zee: Serwite. 1981 .

37. Feingtein $\mathrm{MR}$.

Clindaetrics. Wew Haven: Yale University Press, 1987.

38. Mekeil BJ, Parker $\$$ G.

Decigion ardisis for public bealtb: pribciples and illustrations. han Rev Public Health 1984; $5 * 135-61$.

39. Zarin DA, Pauker SG.

Decision andysis as a bas for wedical decision waking: the tree of Hippocrates. J Med Philosophy 1984; $9: 181-213$.

40. Lamberts 1 .

The International classification of Primary Care. Fan Pract 1987; 4: Honch-news, TW-IX.

41. Anonymous .

ICEPPC-2-defined. Inclusion criteria for the International classification of Heath Probless in Prinary Care. Oxford University Press, 1983 .

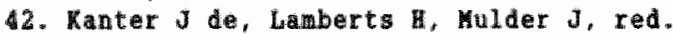

ICPC, International Classification of Primary Care. Nederlandse Vertaling. Concept 1988 . Leiden 1988 .

43. Vel C van, Van den Bosch WJHM, Van den Hoogen HJM.

De Continue Horbiditeit Registratie Wijmegen. Huisarts en Hetenschap 1986; $29: 373-7$.

4. Lamberts 1 , Brouwer H, Groen ASW, Juisman B.

Het tranaitievodel in de huisartspraktijk. Praktiach gebruit van de ICPC tijdens 28.000 contacten. Huisarts en Wetenschap $1987 ; 30$ : $3-11$.

45. Meinstein MC, Fineberg HW.

Clinical decision andysis. Philadelphia: Saunders, 1980.

46. Knottnerus JA.

Principes yan besliskunde. Hieuw Rompas voor de huisarts 1984; II4: $1-15$.

17. Tour-otten $\mathrm{F}$.

Wat doet de dokter? be bijarage wan de aedische besilskunde en protocollen hierbij. Niev hompas voor de huisart 1984; II-5: 115.

48. Meal. C van.

Achllle tot hardloper bekeerd. Huisarts en vetenschap 1981; 24 : $417-23$

49. Crabolder MrJu.

Te leer in de erstelijn [Tnaqurele oratie]. Hastricht: Rijkguniwered teit dibura, 1987.

50. Groot A de, Raottnerus JA.

Hcadenibering van de eerste lijn of vermatschappelijting van de acadevie? Wedisch Contact $1982 ; 37 ; 37-9$.

51. Beusmans GHYI.

tuisarts en liagnostisch centrum, toepassing van werkafspraken door huisartisen [Dissertatie]. Mastricht: Rijksuniversiteit Liburg, 1986 . 
52. Hobus PPK, Schniat HG, Boshuizen MPA, Patell Vh. Contextual factors in the activation of first dignostic hypotheses: expert-movice differences. Medical Education 1987; $21: 471-6$.

53. Verandering verzekerd. stapsgewijs op weq mar een nieum stelse1 van zorg. "s-Gravenhage: Ministerie van Welzija. Volksgezondheid en culturr, 1988. 